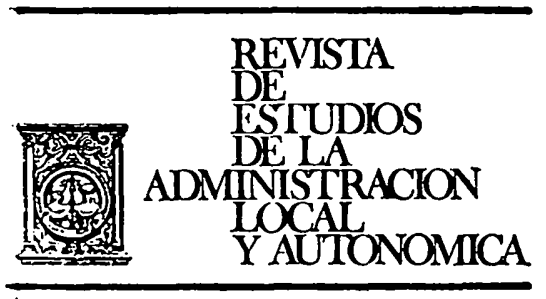

\title{
IV. BIBLIOGRAFIA
}


REALA-1985, núm. 226. BIBLIOGRAFÍA

REALA-1985, núm. 226. BIBLIOGRAFÍA 
Franchetti Pardo (Vittorio): Histo ria del urbanismo, siglos $X I V$ y $X V$. Madrid, Instituto de Estudios de Administración Local, 1985, 596 páginas.

Como ya en alguna ocasión anterior tuvimos oportunidad de señalar, una parte importante de la labor editorial del Instituto de Estudios de Administración Local está dedicada al urbanismo, sin duda, porque éste constituye en la actualidad el más amplio de los sectores de la vida local, hasta el punto que en cierta medida, a través de algunas de las manifestaciones de su plasmación normativa, como el planeamiento y la programación de actuaciones, está afectando a todas las demás áreas de actividad en la Administración local.

En esta oportunidad el Instituto aborda una tarea de mayor calado, como es la de ofrecer una historia del urbanismo, que en el libro recensionado abarca los siglos XIV y XV, y aunque se trate de una obra editada inicialmente en Italia en 1982 -la traducción se debe a Juan Víoque Lozano-, no hay duda que la versión en castellano enriquecerá nuestra bibliografía y facilitará su conocimiento a mayor número de lectores. Precisamente en este punto cabría recordar al organismo editor la conveniencia de que las breves líneas de presentación que contiene la cubierta se hubieran incrementado con una también breve referencia al curriculum del autor que hubiera servido para perfilar los indudables aspectos positivos ante los lectores españoles.

En la breve introducción el autor llama la atención sobre dos temas que nos parecen de interés. El primero hace referencia a que el término urbanismo «indica una disciplina de reciente formación", y en este sentido difícilmente puede relacionarse con los siglos XIV y XV reflejados en esta obra. Se alude en este punto a las encontradas posturas en torno a la separación o acercamiento entre la arquitectura y el urbanismo, resaltadas sobre todo en el mundo académico. En el uso corriente el urbanismo se ocuparía de ula variación de forma o de rol funcional de una ciudad». La arquitectura de «los modos con los que se han edificado algunos edificios o conjuntos urbanos considerados significativos». El autor estima que a nivel teórico general no se puede prescindir de todo el contexto en que se producen ambos, ni siquiera cuando se trate de hacer una especie de historia de cada uno de los aobjetos territoriales". Salvando estas posturas particularistas, se propugna que un estudio como el que se emprende debe proyectarse sobre un fondo pluridisciplinar. En este sentido la whistoria de los tejidos urbanos sería una historia del urbanismo" y encajaría en el marco editorial.

La segunda llamada de atención se produce en torno al hecho de que difícilmente las transformaciones urbanas y territoriales coinciden necesariamente con el corte cronológico que 
supone cada siglo y muchas de ellas responden a periodizaciones y ritmos que son peculiares de aquellos procesos.

A partir de estas reflexiones iniciales el autor decide "conducir la narración del devenir urbanístico europeo durante los siglos XIV y XV por puntos, por problemas y por episodios urbanos». Una de las prescripciones del estudio será precisamente la variabilidad dimensional, funcional, conceptual y tipológica de lo que en estos siglos «se pensaba y se designaba como ciudad" dentro del marco europeo.

La primera parte de la obra recensionada está dedicada a los "Temas y problemas de carácter general», en la que se ponen de manifiesto los aspectos que trascienden de cada espacio territorial concreto, y por ser comunes a todos ellos constituyen el «tejido colectivo de una cultura urbanística que se sitúa y desarrolla a nivel europeon. En esta parte se analizan las líneas y características de los principales asentamientos, así como su localización y dimensión de los centros urbanos más importantes, y dos fenómenos de interés, uno de ellos en vías de desarrollo: el decoro urbano como programa cívico y politico, y otro en declive: la fundación de nuevos centros.

La segunda parte contiene una exposición de los marcos territoriales generales y específicos. El estudio se ordena en secciones geográficas: las áreas italiana; francesa, ibérica -las ciudades hispano-musulmanas y las ciudades españolas después de la $\mathrm{Re}$ conquista-; inglesa; flamenca-holandesa-germánica; áreas europeas centrales -Polonia, Checoslovaquia-, y áreas europeas orientales.

La tercera parte se titula «Signos y experiencias para una nueva ciudad».
Sus dos capítulos, "La cultura urbanística italiana» $\mathrm{y}$ "Un producto del Renacimiento italiano: la ciudad como proyecto", se ofrecen como resultados de la reflexión sobre el fenómeno de la difusión de la cultura urbanístico - renacentista italiana en la frontera entre la Baja Edad Media y los albores de la Edad Moderna.

El libro se complementa con ilustraciones y suficiente documentación. gráfica que dan amenidad a toda la: obra, aunque en muchos casos no pertenezcan -por la práctica inexisten cia de este tipo de documentos- a las épocas estudiadas, pero que aun siendo de siglos posteriores ofrecen: -como dice el autor- auna imagen plausible de la ciudad en una época. anterior».

Por último, unas páginas de bibliografía y los índices general y geográfico de ciudades estudiadas completan esta importante aportación a la historia del urbanismo, que sin duda será de gran ayuda a los estudiosos der tema.

\section{Paulino Martin Hernández}

Martí Mateo (Ramón), Gordillo. (Agustín R.), BandeIra DE MELlo (Celso-Antonio) y otros: Derecho municipal iberoamericano. Presentación por Luciano Parejo Alfonso, Madrid, IEAL, 1985, XVI, 1.174. páginas.

En el mes de mayo de 1983 se reunieron en Madrid los profesores de Derecho administrativo de los países. iberoamericanos en la sede del Instituto de Estudios de Administración Local obedeciendo a los criterios de actividades iberoamericanas de dicho organismo y al programa de desarrollo tecnológico diseñado por el prof:- 
sor Martín Mateo. De esta reunión de especialistas surgió la necesidad de actualizar y sistematizar anteriores intentos de un Derecho municipal iberoamericano.

En el Congreso fueron abordadas las cuestiones más relevantes que la organización y el funcionamiento de las estructuras locales suscita, entre ellas la autonomía local y los proble. mas de financiación, así como la democratización de las estructuras políticas y la participación ciudadana. Gran interés tuvieron aquellos debates, de los cuales salió el acuerdo de elaborar el presente volumen, que en realidad es un Manual de Derecho municipal iberoamericano respondiendo a su título, como seguidamente glosaremos.

Comienza la obra con el prólogo de Luciano Parejo Alfonso, Director del Instituto y artífice del Congreso, pues en realidad se trató de un Congreso de profesores de Derecho administra. tivo, aunque en principio se anunciase con una rúbrica más modesta, en el que señala las razones de la reunión, así como los satisfactorios resultados obtenidos, fijando el compromiso con los iberoamericanos asistentes a hacer realidad el libro Derecho municipal iberoamericano.

El primer trabajo que aparece es la conferencia de clausura del Congreso, pronunciada por el Ministro de Administración Territorial de España y profesor de Derecho administrativo, don Tomás de la Quadra Salcedo, bajo el epígrafe «Situación actual y perspectivas de la Administración local».

Su intervención era muy importante para conocer la opinión que sobre los problemas del Régimen local ostentaban las autoridades recién incorporadas al Ministerio de Administración Territorial, pues cuando el Con- greso se clausuró hacía poco tiempo que se habían cumplido los cien días de cortesía que todo Gobierno disfru. ta en su andadura. El panorama del Régimen local que ofrecía el titular de la cartera del ramo suponía llevar a cabo una reforma profunda del mismo que tomara como inspiradores los principios constitucionales, cuestión que quizá pueda parecer obvia, pero debe tenerse en cuenta la larga historia de proyectos y leyes de Régimen local frustradas y que en 1983 estaba parcialmente en vigor la Ley de Régimen local del sistema político anterior.

Concretados los principios, hacía de la dualidad autonomía financiera y autonomía municipal las premisas más importantes sobre las que debían girar los planteamientos del nuevo texto legal, que estaba en elaboración y a punto de presentarse a las Cortes para su tramitación parlamentaria.

La segunda parte de su intervención la dedicó a la descripción material del Proyecto de Ley de Régimen local, que era el empeño máximo de él y de su equipo. Advierte que no hay un listado de materias competenciales según la fórmula tradicional, porque en la actualidad no existen materias propias de la vida local, pues la experiencia ha demostrado que lo que existe es una intercomunicación «que en la práctica el Estado, a través de sucesivas regulaciones, ha ido extrayendo de este listado de materias, competencias que acababa ejercitando el propio Estado». En consecuencia, lo que se proclama «es una consecuencia del principio de la autonomía local aplicada a nuestra realidad actual, el principio que necesariamente toda legislación sectorial que regula actividades y materias sectoriales debe de atribuir a los En- 
tes locales, un ámbito de intervención y participación que satisfaga el principio de autonomía local que se concreta en el derecho a participar en la satisfacción de sus propios intereses, pero que tiene que articularse con los derechos y con las competencias de otras instancias superiores».

El concepto es realmente moderno, lo que junto con su realismo hacía llegar a la conclusión que el Proyecto de Ley resultante, como así fue, pese a las naturales suspicacias y los posibles sentimientos patrimoniales $y$ corporativistas, iba a resultar un intento verdaderamente eficaz para resolver el problema del Régimen local español, auténtica revolución pendiente desde el siglo pasado. Afortunadamente en esta ocasión los deseos y las intenciones se convirtieron en realidad.

Ahora bien, el ámbito y el aspecto organizativo del Régimen local no se agota con la regulación estatal, entonces Proyecto, hoy Ley, incluso en la misma se prevé que las Comunidades Autónomas completen ese desarrollo organizativo. Interesantes consideraciones se realizan sobre la impugnación de actuaciones, régimen jurídico de los funcionarios, el papel del Municipio en la democratización de las estructuras del Estado, concretamente en España, etc.

Los aspectos del Derecho municipal comparado comienzan con el trabajo del profesor Martín Mateo «El Régimen local español», en el que hace una consideración a los antecedentes del siglo pasado y de la presente centuria, tanto el Estatuto de Calvo Sotelo como la legislación franquista. El segundo capítulo lo dedica al Régimen local en el nuevo orden constitucional, diferenciando la autonomía, las competencias estatales y su normativa básica, las competencias de las Comunidades Autónomas y la normativa actual.

Sabido es que en España el escalón tercero de la Administración está constituido por la Provincia, considerado también como Administración local; ello ha supuesto que el profesor Martín Mateo hiciese una descrip. ción de tal Entidad local de acuerdo con su tipología en España. Los puntos considerados son: La Administración provincial, Naturaleza jurídica de la Provincia, Configuración orgánica de la Provincia, Las Diputaciones Provinciales y Las Comunidades Autónomas.

Respecto al Municipio, describe sus conceptos, elementos, capacidad, competencia y regímenes especiales, dedicando un último epígrafe a la reforma del Régimen local.

El profesor Agustín G. Gordillo es el autor del trabajo aLa Administración local argentina", el cual se articula a partir del estudio y consideración del ordenamiento básico y las fuentes constitucionales. Los siguientes epigrafes son: Distribución territorial, Organos de gobierno y administración municipal, Autonomía y tutela administrativa, Competencias y atribuciones, Finanzas, Régimen de empleo municipal, Regímenes locales especiales, Urbanismo, La tendencia al cambio y el Movimiento vecinal.

Es de destacar que la situación argentina en los momentos en que el profesor Gordillo redacta su trabajo era muy parecida a la de España en los primeros tiempos de la transición, con un proceso de cambio y reforma de todas las instituciones del país, anquilosadas por el quietismo, que naturalmente afectaba a la Administración municipal, de ahí que dedique los dos últimos capítulos a temas y cuestiones por otro lado de gran actualidad $\mathrm{y}$ vigor. 
Celso-Antonio Bandeira de Mello, profesor de la Universidad de Sao Paulo, aporta «O Municipio no Direito brasileiron, explicando la tipología lo cal de su país a partir de una introducción basada en la articulación constitucional brasileña. En el capítulo dedicado a la autonomía política describe los órganos de gobierno municipal, el poder de expedir sus propias leyes y las competencias privativas sobre las materias de sus peculiares intereses. La autonomía administrativa comprende el aparato burocrático y el personal respectivo, así como la disposición sobre sus propios bienes. Le siguen los capítulos dedicados a la autonomía financiera, los límites a la autonomía municipal, control del Municipio, Regiones metropolitanas y la realidad municipal del Brasil.

La Administración local en Colombia es tratada por el profesor Jaime Vidal Perdomo estudiando la organización departamental, que comprende los Departamentos, las Intendencias y las Comisarías. Siendo descritas cada una de ellas, así como sus funciones y recursos. Las autoridades departamentales son la Asamblea y el Gobernador, dualidad administrativa en el que una adopta las decisiones generales y el Gobernador las ejecuta. Concluye el capítulo con el estudio de los actos de las Asambleas, su integración y sus funciones.

El segundo capítulo lo dedica a la Administración municipal, estudiando en primer lugar el Municipio como unidad territorial de Administración, seguido de las funciones del Municipio, en cuyo epígrafe incluye: prestación de servicios públicos, facultades en relación con el urbanismo, normas para el equilibrio campo-ciudad y normas de policía. El capítulo tercero se dedica a la potestad impo- sitiva de los Municipios. El cuarto a las autoridades municipales, distinguiendo los Concejos municipales, los Alcaldes municipales, los Personeros municipales y el Tesorero y Contralor municipal.

En el quinto capítulo estudia las «nuevas formas de Administración municipal», dedicando un epígrafe al caso de Bogotá titulado «El distrito especial de Bogotán, con exposición de toda la casuística que en los últimos tiempos ha dado este problema, así como la necesidad de un estatuto particular y las interpretaciones de la Corte de Justicia sobre el alcance del distrito especial. Entre las nuevas formas de Administración municipal distingue: las áreas metropolitanas, las asociaciones de Municipios, las distintas categorías de Municipios y las Juntas Administradoras locales.

El catedrático de Derecho administrativo Eduardo Ortiz Ortiz es el autor de la monografía dedicada a la "Municipalidad en Costa Rica». Se trata de un amplio trabajo que recoge toda la problemática municipal costarricense, basada en la Constitución de 1949 y en el Código Municipal de 4 de mayo de 1970 .

En el capítulo primero, "Concepto y elementos», describe el munícipe o vecino, el grupo o comunidad vecinal y el cantón, la Municipalidad, la Corporación, lo local, la autonomía y el concepto básico de la Municipalidad. Hace seguidamente un examen de las cuatro notas fundamentales del Ente municipal estudiando la Corporación como Ente público, el Ente territorial, la Municipalidad, Ente público no estatal independiente o relevante y la competencia local. El capítulo tercero trata de la «Organización constitucional y legal de los Municipios" y el cuarto "De las relaciones de la Municipalidad». 
Don Enrique Silva Cimma es una importante autoridad del Derecho administrativo iberoamericano $\mathrm{y}$ además es uno de los líderes más caracterizados de la resistencia democrática chilena. Sus intervenciones en el Congreso fueron escuchadas con sumo respeto y su indudable maestría surgió permanentemente. El trabajo que aporta en el presente libro lleva por título "Los problemas de la Administración local iberoamericana. Breve explicación introductoria de la situación chilena». Esta situación, excepcional como es sabido, condiciona enormemente la problemática municipal de Chile, pues el sistema autoritario ha dado unas nuevas formulas legales que regulan las Municipalidades a partir de la Constitución de marzo de 1981 y anteriormente con el Decreto-ley 1.289 de 1975. Todo ello supone, en opinión del autor, la ausencia de autonomía municipal, y en lugar de tutela afirma que existe dependencia directa. De cualquier forma, y por estas circunstancias, remite el autor a una obra más amplia del profesor Cumplido Cereceda La estructura institucional del modelo de descentralización.

El Régimen municipal ecuatoriano es estudiado por el profesor Francisco Tinajero, el cual lo articula de la siguiente forma: Concepto y fines del Municipio, El vecindario, El territorio, El bien común local, Gobierno municipal, Personalidad jurídica y Patrimonio propio. El segundo capitulo lo dedica a la Constitución, fusión y supresión de Municipios. El tercero a la Autonomía municipal, distinguiendo la soberanía, la autonomía y la autarquía, así como las garantías de esta última. Finaliza con unas consideraciones relacionales de la Municipalidad con el Estado.

Alfonso Nava Negrete, profesor me- xicano, es el autor del trabajo titulado "Los Municipios en México». Parte de la Constitución de 1917, en la que el Municipio figura como la institución más importante de la vida social, política, jurídica y económica de México. Es por tanto factor decisivo en el Municipio mexicano y en su estudio la fuente constitucional, así como las sucesivas reformas del mismo a través del texto básico federal. Continúa con el Régimen jurídico del Municipio, Los órganos de gobierno municipal, La autonomía hacendaria de los Municipios y Las posibilidades de reforma en el proceso legal incurso en el México de nuestros días.

El profesor de Derecho administrativo de la Facultad de Ciencias Sociales de la Universidad Nacional de Asunción, Enrique Chase Plate, es el autor del estudio sobre «El Municipio paraguayo", que lo describe teniendo en cuenta los siguientes factores: Ordenamiento básico. Elementos esenciales. Organos de gobierno municipal. Procedimiento de acceso al órgano de gobierno. La autonomía municipal en la Constitución y en la ley. Leyes más importantes relacionadas con la Administración local. Régimen de la función municipal. Regímenes locales especiales. Urbanismo. Tutela administrativa. Control judicial. Competencias y atribuciones. Finanzas. Areas metropolitanas. Tendencias al cambio y reformas aconsejables sugeridas por la doctrina.

«El Régimen municipal en la República Oriental del Uruguay» es el trabajo que aporta el profesor Daniel Hugo Martins, el cual comienza con una consideración histórica a la importancia del Cabildo y su papel en el proceso independentista. Continúa con Las normas constitucionales vigentes, Los órganos de gobierno muincipal, La autonomía y tutela admi- 
nistrativa, El control judicial, Las competencias y atribuciones, Las finanzas, El Estatuto de Funcionarios y El Urbanismo.

El Director del Instituto de Derecho Público de la Universidad Central de Venezuela Allan Randolph Brewer-Carias aportó un extenso y completo trabajo sobre «El Régimen municipal en Venezuela".

El lugar del Municipio en la organización del Estado federal venezolano es el primer capítulo estudiado por el profesor Brewer, así como su categoría como poder público dentro de la distribución vertical del poder. El siguiente escalón será, lógicamente, el desarrollo del papel del Municipio en la Constitución, punto de partida para la existencia de una autonomía municipal en el aspecto político, en el normativo, en el tributario y en el administrativo. Cerrándolo con la organización municipal y el autogobierno local, aunque en el primero de los casos señale la ausencia de autonomía organizativa en el uniformismo municipal y en la inejecución constitucional del principio de la organización municipal.

El- territorio es el siguiente factor estudiado, cómo se articula éste desde los Municipios; con sus procesos de creación, fusión y extinción; hasta las Mancomunidades, pasando por los distritos metropolitanos.

Amplia descripción hace de las: materias que son competencias municipales, cuya enumeración es la siguiente: urbanísticas, abastos, circulación y transporte urbano, cultura, salubridad, asistencia social, institutos populares de crédito, turismo y policía municipal. Todas ellas según su carácter concurrente. Además incluye las que se encuentran en el régimen de competencias en la Ley Orgánica, así como su sujeción a la legislación nacional. Entre éstas cita: acueductos, cloacas y drenajes, distribución y venta de electricidad y gas, transporte colectivo de pasajeros y circulación urbana, servicio de mercadeo y abastecimientos, aseo urbano y domiciliario. El Régimen del gobierno y administración municipal cierra esta primera parte del estudio. Continúa con las Haciendas municipales y una profunda descripción de la misma, así como del Régimen de bienes municipales. Todos los aspectos presupuestarios y de contabilidad municipal son estudiados en el capítulo quinto, dedicado al "Sistema administrativo de los Municipios».

La participación es una de las cuestiones que preocupa extraordinariamente en toda el área iberoamericana, como así nos lo han mostrado los diversos autores y profesores a los cuales hemos tenido la oportunidad y el honor de escuchar en los últimos tiempos; esta preocupación se agudiza en el caso de Venezuela, y el ilustre profesor Brewer-Carias no podía olvidar en su sintesis incluir un capítulo al respecto, considerando fundamentalmente la participación politica prevista en la Ley Orgánica de Régimen local y: en las Asociaciones de Vecinos.

El capítulo séptimo estudia las. peculiaridades del contencioso-administrativo municipal en Venezuela. El control es otro de los factores que determinan según su sistema y. procedimiento el grado de autonomía municipal que existe en un país. En este caso se prevé en los artículos 29 y 206 de la Constitución que los actos de los Municipios no pueden ser impugnados sino ante los órganos jurisdiccionales, lo que supone la ausencia de tutela.

Dentro de la filosofía municipalista, de la que Brewer es probablemente 
uno de los máximos exponentes en los países de habla hispana, incluye un capítulo dedicado a recoger algunos aspectos de la crisis del municipalismo, entre los que señala tres casos: la crisis de la representatividad política de los Municipios, la de la participación política en los Municipios y la de la autonomía derivada de la ausencia de descentralización. Hace una evaluación crítica de la Ley Orgánica de Régimen Municipal de Venezuela, señalando los defectos y fallos de la misma, al mismo tiempo que propone la reforma de las instituciones locales.

Pero este último apartado lo desarrolla con mayor amplitud en el capítulo noveno, «Bases para la reforma del Régimen municipal en Venezuela», y esta reforma sólo se puede hacer superando el uniformismo en el régimen organizativo municipal, en la configuración de las Entidades locales y en el sistema electoral de representación proporcional, así como el régimen colegiado de gobierno y administración local. Concluye la parte doctrinal de su exposición con un último capítulo dedicado al Régimen municipal del Distrito Federal, con una flexión histórica y la exposición de su regulación actual, incluyendo los problemas y aportando algunas soluciones, entre las que figuran la metropolitanización del régimen de Caracas y la descentralización política del régimen de Caracas.

El apéndice documental de la obra comprende prácticamente la mitad de la misma, y con gran acierto se ha recogido la aportación de los autores, los cuales han facilitado los textos legales, que son fundamentalmente las referencias constitucionales al Régimen local y los textos específicos de Régimen local.

El colofón de la obra ha corrido a cargo de Luciano Parejo Alfonso, el cual ha publicado un importante trabajo sobre «La reforma del Régimen local en España". Las razones que abonan esta aportación quedan recogidas en nota de los editores, en la que señalan las circunstancias históricas de la reforma local española, ya que han coincidido la publicación de esta obra con la aprobación y publicación oficial de la Ley de Régimen local española, y ya se anuncia que aunque este trabajo es un prólogo, puede ser el punto de partida de posteriores Tratados.

Parejo sintetiza perfectamente las características del Régimen local antes de la transición política a la democracia y la evolución del mismo durante dicha transición y fundamentalmente a partir de la Constitución de 1978. En consecuencia, al elaborarse el Proyecto de Ley que hoy se ofrece a los españoles como máxima norma reguladora del Régimen local se tuvieron en cuenta los siguientes aspectos: Cuestiones de interpretación constitucional y de política legislativa, las competencias legislativas estatales en la materia y su alcance -recuérdese a estos efectos el primer trabajo considerado, del que es autor el Ministro de Administración Territorial, profesor De la Quadra Salcedo-, el contenido del Régimen local como materia legislativa y la posición de los Entes locales en la organización territorial del Estado. Todo ello configuró y determinó las líneas básicas de la regulación del Proyecto de Ley en las siguientes cuestiones: La ordenación territorial, la autonomía local, la descentralización, la organización y gobierno de las Corporaciones locales, las relaciones interadministrativas, la información y la participación ciudadana y la función pública.

Creemos sinceramente que este vo- 
lumen supone una revisión muy importante y sobre todo modernizadora de anteriores intentos de elaborar un Tratado de Derecho comparado; recordemos a Marqués Carbó, Albi, etc. Es de esperar que en lo sucesivo estas revisiones doctrinales sigan la dinámica social de los pueblos con mayor simultaneidad y no se demoren años y años las actualizaciones. Sería conveniente fijar en diez años la repetición del evento y la reedición de la obra.

E. 0 .

Pareja i Lozano (Carles): Contenido $y$ alcance de los Planes Especiales de Reforma Interior en el Sistema de Planeamiento Urbanistico. Madrid, Instituto de Estudios de Administración Local, 1984, 120 págs.

El suelo urbano, ya se ha repetido con insistencia, es el gran olvidado en nuestra actual législación urbanística, que sigue pensando en los ensanches o crecimientos sobre nuevos terrenos, libres, por tanto, de los problemas que se acumulan en las áreas ya ocupadas por la edificación y los servicios urbanos. Este vacío no deja de ser paradójico - también se ha insistido en ello- en unos momentos en que por múltiples causas, y una de ellas la crisis económica de los últimos años, la actividad urbanística se concentra en esta clase de suelo. Sin duda en estos tiempos el suelo más desprotegido de instrumentos de gestión es el que con mayor intensidad recibe la atención de los agentes urbanísticos.

Quizá la única excepción a estas afirmaciones generales sea el mayor detenimiento con que la relativamente nueva legislación urbanística contempla una figura como la de los Pla- nes especiales, figura, por otra parte, si no única, sí al menos de especial relieve para la ordenación del suelo urbano, donde está llamada a desarrollar un interesante papel sobre todo en aquellas ciudades en que por la extensión del territorio o por la situación urbanística del conjunto se haga preciso acudir a este tipo de planeamiento para rematar, renovar o remodelar determinadas áreas, a las que el Plan General en muchos casos úincamente se referirá para establecer la delimitación de las mismas.

Estas razones hacen que en los últimos años no sean pocos los estudiosos que han elegido como objeto de análisis y reflexión la figura del Plan Especial. En este marco encaja la obra que recensionamos, y que dada la actualidad del tema debe ser saludada con alborozo. El propio autor dirá en las primeras líneas de presentación de su trabajo que ala consideración de los núcleos urbanos consolidados de nuestros pueblos y ciudades... constituye, sin duda, uno de los retos fundamentales del urbanismo actual».

El capítulo primero de los cinco que completan el texto está dedicado al análisis de la reforma interior de poblaciones en el proceso de formación histórica del Derecho urbanístico, preocupación que aparece de forma tardía en nuestra legislación y de la que cabe indicar la insuficiencia de las medidas con que se apoya, pero que en todo caso va a establecer un largo proceso que abarca desde la sustitución o renovación pura y simple de partes del tejido urbano a las actuales tendencias de rehabilitación y revitalización de áreas, a las que se ha llegado no tanto por aplicación de la propia legislación urbanística, sino a consecuencia de una más acusada sensibilidad social por los temas de 
preservación y protección de lo que constituye el patrimonio edificado histórico. Precisamente a esta nueva orientación cabe achacar la cada vez más escasa utilización de figuras como el Registro de Solares o la declaración de estado de ruina, a las que el autor se refiere como mecanismos de intervención urbanística "de idoneidad más que discutible».

Sin duda, los capítulos tercero y cuarto son los que suponen mayor atractivo dada la actualidad de los temas que abordan. En el primero de ellos se estudian las operaciones de reforma interior en la vigente legislación urbanística, señalando la imprecisión legal respecto a la conceptuación de la reforma interior, de la que ya hemos hablado anteriormente, lo cual no será óbice para que la Administración defina el alcance y contenido de estas operaciones en ejercicio de su potestad de planeamiento. Al estudiar la regulación legal del contenido material de las operaciones de reforma interior el autor analiza por separado los Planes especiales para llevar a cabo «actuaciones aisladas» y las que tienden a la realización de «operaciones integradas», distinción establecida en el Reglamento de Planeamiento, y que sin duda es de interés tanto por lo que se refiere a la regulación del contenido material de aquellos Planes como a la vinculación de los mismos con el Plan General. Conviene resaltar en este punto la postura del autor frente a otros que se venían manteniendo con insistencia - aunque este aspecto no dejara de ser polémico- respecto a la no necesaria y automática aplicación de los estándares de los Planes parciales a las áreas ordenadas con Planes especiales, lo cual no quiere decir que la Administración, en uso de su potestad de planeamiento, no pueda aplicar análogos criterios para el destino o reserva de suelo.

En el capítulo cuarto, en el que se relacionan los PERI con el sistema de planeamiento de la Ley del Suelo, el autor defiende posturas avanzadas. al mantener la posibilidad de que aquéllos introduzcan alteraciones deP planeamiento general sin tener que sujetarse al procedimiento de modificación de éste. En todo caso se distinguen los supuestos de actuaciones aisladas y los de operaciones integradas previstas o no por el Plan General. En la misma línea constituye una aportación de interés la última parte del capítulo referido a la relación entre los PERI y el planeamiento general dentro del sistema normativo urbanístico.

El último capítulo, más reducido en contenido, hace referencia a la redacción y formulación de estos Planes.

Para concluir podemos indicar que aunque se trata de un estudio parcial de los Planes especiales, aborda sin duda los aspectos de mayor interés, y dada la actualidad del tema, la claridad con que se presentan las posturas mantenidas y la operatividad y, en consecuencia, influencia práctica de muchas de las cuestiones analizadas, la obra recensionada no sólo será de utilidad para los estudiosos o los teóricos del urbanismo, sino para quienes desde el planeamiento se enfrentan con la tarea de hacer más habitables nuestras ciudades al erradicar bolsas de degradación urbana en unas áreas a las que atienden los Planes ahora examinados.

Paulino Martín Hernández

LÓPEZ-Nieto y Mallo (Francisco): $\mathrm{HO}$ nores y protocolo. Madrid, $\alpha \mathrm{El}$ Consultor de los Ayuntamientos y de 
los Juzgados», 1985, 628 págs., $24 \times$ $16,8 \mathrm{~cm}$.

He aquí una obra más de un prolífico autor avezado al tratamiento de una amplia serie de materias que tan particular interés ofrecen a todos cuantos giran en la órbita de lo local. Bajo su consideración han desfilado Gobiernos civiles, asociaciones, procedimientos de demolición y obras en fincas urbanas, espectáculos y establecimientos públicos, seguridad ciudadana, sanciones municipales, procedimiento administrativo, etc. Con $\mathrm{Ho}$ nores y protocolo Francisco LópezNieto sitúa un nuevo jalón en la trayectoria de su pluma con fortuna y oportunidad.

Sin que la distinción pretenda ser en modo alguno rígida - no podría serlo-, cabe advertir la existencia de libros que forman junto a la de libros que informan. La obra Honores y protocolo es esencialmente catalogable en el segundo grupo, como corresponde a su carácter eminentemente práctico; pero no deja de participar de las características que configuran a un libro de formación. Sucede que la materia -mejor se diría las materias- a que el autor se refiere es de índole histórica en su mayor parte, y no cabe liberarla en su aspecto pragmático de los orígenes, evolución, fines y procedimientos de tantas instituciones como el libro recoge. $Y$ ahí reside una de las dificultades que han de afrontar los autores de obras de este tipo: enmarcarse en la necesaria ponderación entre gnosis y praxis, efecto felizmente conseguido en este caso, del que ha resultado una guía de aplicación práctica, pero con las necesarias referencias históricas, que son, como la sal, condimiento que presta al producto amenidad y acrece su utilidad.
A otra dificultad se ha aludido más arriba: la amplitud del campo tratado, que tanto abarca a la nobleza como a los partidos políticos, a la organización del Estado como a los actos sociales. Tal conjunto de realidades no puede recibir un tratamiento unitario sin que se resienta la precisión de conceptos o sin caer en vacíos lamentables. En efecto, la necesidad de manejar una «óptica interdisciplinar" es insoslayable en esta obra, y el autor se ha cuidado de aludir a ello en el prólogo como especial justificación de la distribución, contenido y extensión de los distintos capítulos. Consignamos con satisfacción la humilde y personal apreciación de que López-Nieto ha salido airoso de un empeño difícil que pone al alcance de muchas manos -las profesionales serán las más beneficiadasuna obra plenamente lograda.

A una Introducción que establece precisiones terminológicás y que hacé una presentación de las Distinciones sociales y su simbología, de los honores inherentes a aquéllas, del protocolo y del plan de la obra, sigue el cuerpo de ésta con un Título Preliminar dedicado a La Corona (el Rey, la Familia Real, la Casa del Rey y los Honores de la Corona). El Título Primero, referido a las Distinciones sociales, dedica el Capítulo 1 a la Presidencia del Gobierno, Cortes generales (Cámaras, Defensor del Pueblo y Tribunal de Cuentas), Gobierno y Administración del Estado 'Ministros, órganos centrales y periféricos), organismos autónomos y carrera administrativa, Tribunal Constitucional y Poder judicial, Fuerzas Armadas y Administraciones autónomas, provinciales y locales. Al sector privado dedica dicho Título Primero su Capítulo 2: Estudios universitarios, Corporaciones públicas (Instituto de Espa- 
ña, Universidades, Colegios profesionales, Cámaras oficiales, etc.), Asociaciones de interés general (partidos políticos, asociaciones empresariales y sindicatos de trabajadores), Asociaciones voluntarias (de interés público y del mundo mercantil) y la Iglesia católica (la Santa Sede, la organización eclesiástica, la jerarquía y la Conferencia episcopal). El Capítulo 3 está dedicado a los títulos nobiliarios y. a la nobleza, sea titulada, no titulada y de cargo. $Y$ se cierra el Título con el Capítulo 4, dedicado a las diversas Ordenes y Maestranzas y a las condecoraciones.

El Título Segundo, Simbología de las distinciones, reserva su Capítulo 1 a Banderas e himnos (himno y enseña nacionales, otros himnos y enseñas, insignias y distintivos públicos y privados), recoge en el Capítulo 2 la Simbología heráldica (oficial, de la nobleza y de Corporaciones y asociaciones) y trata en el Capítulo 3 la Indumentaria personal (uniformes civiles y militares, nobiliarios, eclesiásti$\cos$ y las normas de etiqueta y uso de las condecoraciones).

El Título Tercero, Honores inherentes a las distinciones, dedica su Capítulo 1 a los tratamientos honoríficos civiles, militares; eclesiásticos y de la nobleza; 'el capítulo 2 a la ordenación de las precedencias según el tipo de acto, la autoridad, el organismo o el lugar en que aquél se desarrolla, y cierra el Título el Capítulo 3, reservado a los Honores militares.

El Título Cuarto, el último, sobre el Protocolo en los actos públicos, expone en el Capítulo 1 la organización del protocolo oficial y privado con arreglo a la Ley y a los usos; dedica el Capítulo 2 a los actos públicos oficiales (recepciones, tomas de posesión, fiestas), y describe en el Capítu- lo 3 el desarrollo y protocolo de los actos públicos oficiales o privados al aire libre, en locales cerrados (congresos, banquetes y actos corporativos, bodas, bautizos, aniversarios, defunciones, etc.).

Un complemento utilísimo de lo que antecede lo constituyen las dos partes que siguen, preparadas por el editor de este libro: una, sobre Formularios en relación con los títulos nobiliarios, condecoraciones, escudos y honores municipales y organización de actos públicos o de ruedas de prensa, y otra parte que recoge la Legislación fundamental sobre las materias principales de esta obra. Los Indices analítico y general complementan el volumen y facilitan su manejo.

Juzgamos hallarnos ante una obra bien necesaria, precisamente por su generalidad, tanto como por su concisión, que orienta y resuelve puntos que se presentan al paso a diario, convirtiéndose en un libro de primera mano: en un manual. Se nos ocurre sugerir al autor que en una próxima reedición, que le auguramos cercana, recoja con el dominio y soltura en él habituales, el aspecto del hermanamiento de ciudades. Dado que éste nace de un reconocimiento de afinidades históricas, artísticas y culturales, que ha desembocado en un procedimiento de común vinculación a su memoria para exaltar la solidaridad intermunicipal, no nos parece muy alejado de los propósitos del libro señalar a sus usuarios ese procedimiento, establecido para crear y desarrollar tal vinculación intermunicipal. La cual significa, por otra parte, enaltecimiento y timbre de nobleza por el momento y asimilación de culturas distintas y a la vez comunes - complementarias que comporta. Esta observación, sujeta naturalmen- 
te a una apreciación muy personal, se consigna ayuna de toda impertinencia en sus propósitos: en definitiva, el criterio del autor comentado puede ser muy otro y plenamente respetado, desde luego, por quien formula esta sugerencia. Una de las posibles objeciones oponibles es, por supuesto, aceptable. En efecto, harto se ha extendido por campos tan dispares e intrincados, dando a la luz una obra clara, concisa - ya se ha dicho-y altamente orientadora. De acuerdo con la declaración de intenciones formulada en el prólogo, ha de quedar relegado a un tratado, o a muchos tratados, el estudio profundo y prolijo de cualquiera de las materias de la obra, con destino a estudiosos y curiosos.

Merece una especial mención «El Consultor de los Ayuntamientos y de los Juzgados», editor con ésta de otras varias obras del autor, que al sacarla a la luz revela la fidelidad a su postura de constituirse en incansable alivio y ayuda del profesional que necesita medios de primera mano para afrontar su dura tarea diaria, endu-. recida por una inestabilidad legislativa que se complica por dos fenómenos en cierto modo opuestos: la profusión y las lagunas que a su paso ha dejado.

Hay que advertir, por último, que los juicios que anteceden no van en detrimento de obras de este tipo preexistentes, alguna editada por este propio Instituto de Estudios de Administración Local, muy necesarias también, limitadas a campos más estrictos que los contemplados por la que motiva estas líneas.

C.-E. R. DEL C. Y DE N. 


\section{REVISTA DE ADMINISTRACION PUBLICA}

\section{(CUATRIMESTRAL)}

\section{CONSEIO DE REDACCION}

Presidente: Luis JORDANA DE POZAS ( $t$ )

Manuel Alonso Olea - José Matía Boquera Oliver - Antonio Carro Martínez - Manuel F. Clavero arevalo - Rafael Entrena Cuesta - Tomás R. Fernández Rodríguez - Fernando Garrido. Falla - Jesús González Pérez - Ramón Martín Mateo - Lorenzo MartínRetortillo Baquer - Sebastián Martín-Retortillo Baquer - Alejandro Nieto - José Ramón Parada Vázquez - Manuel Perez Olea - Fernando Sainz de Bujanda - Juan A.

Santamaría Pastor - José luis Villar Palasí

Secretario: Eduardo GaRcía de ENTERRfa

Secretario adjunto: Fernando SAINZ MORENO

SUMARIO DEL NUM. 106 (enero-abril 1985)

\section{ESTUDIOS:}

Ramón Martf́n Mateo: «Régimen jurídico de los cultivos marinos».

PEdRo Escribano Collado: «Ocupación temporal».

Juan Ignacio Astarloa: «Teoría y práctica de los Decretos-leyes en el Derecho españols.

Roberto Parejo Gamir: «Transmisión y gravamen de concesiones administrativas».

antonio Cano Mata: "Los ciudadanos y su posible intervención en el recurso de amparo y demás impugnaciones residenciadas en el Tribunal Constitucional».

\section{JURISPRUDENCIA:}

I. Comentarios monográficos:

Juan Eugrnio Soriano: «El enjuiciamiento de la actividad parlamentaria no logislativaw.

Juan Rodrfguez Drincourt: «Edificios ruinosos en el dominio público estatal de las playas».

II. Notas.

CRONICA ADMINISTRATIVA.

BIBLIOGRAFIA.

PRECIOS DE SUSCRIPCION ANUAL

$\begin{array}{lllllllllllllll}\text { España } & \ldots & \ldots & \ldots & \ldots & \ldots & \ldots & \ldots & \ldots & \ldots & \ldots & \ldots & \ldots & \ldots\end{array}$

2.300 pesetas

$\begin{array}{lllllllllllll}\text { Extranjero } & \ldots & \ldots & \ldots & \ldots & \ldots & \ldots & \ldots & \ldots & \ldots & \ldots & \ldots & 29\end{array}$

$\begin{array}{llllllllll}\text { Número suelto } & \text { España } & \ldots & \ldots & \ldots & \ldots & \ldots & \ldots & \ldots & \ldots\end{array} \quad 950$ pesetas

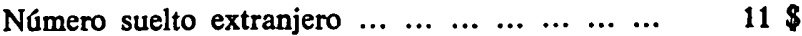

CENTRO DE ESTUDIOS CONSTITUCIONALES

Plaza de la Marina Española, 9 28013 MADRID (España) 